\title{
ORLANDI, Eni P. Língua e Conhecimento Lingüístico. Para Uma História das Idéias no Brasil. São Paulo, Cortez, 2002.
}

\author{
Maurício Silva \\ Universidade de São Paulo
}

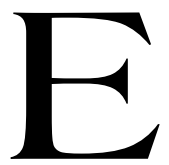

mbora apenas recentemente a Historiografia Lingüística - área do conhecimento que não se confunde com a História da Lingüística, nem com a Lingüística Histórica tenha se tornado objeto de estudo mais sistemático no Brasil, tal abordagem dos estudos da linguagem tem ganho cada vez mais adeptos, já apontando para a conformação de uma tradição local nesse campo de pequisa. Pioneira nas novas abordagens propostas pela Historiografia Lingüística - apesar de preferir a denominação História das Idéias Lingüísticas -, Eni Orlandi, como demonstra seu mais recente livro (Lingua e Conbecimento Lingüístico. Para Uma História das Idéias no Brasil. São Paulo, Cortez, 2002), tem contribuído sobremaneira para a divulgação de pesquisas nessa área de estudos.

O livro referido dividi-se em dois tópicos, os quais já estão sugeridos em seu título: o primeiro, destinado a considerações sobretudo de natureza teórica, relativas à língua como espaço de conflitos e representações (éticos, simbólicos, identitários); o segundo, de natureza mais "prática", destinado ao estudo do saber metalingüístico como marca de determinação da língua portuguesa no Brasil.

Com o objetivo de analisar a constituição da língua portuguesa, a partir da produção das idéias lingüísticas no Brasil, a autora afirma, entre outras idéias, que as gramáticas aqui produzidas possuem filiações que indicam compromissos teóricos, filosóficos e 
ideológicos, destacando sobretudo o papel desempenhado pelo positivismo e pelo naturalismo na constituição, no século XIX, das gramatização de nossa língua. Assim, a autora se propõe a articular a história do saber metalingüístico à constituição da língua nacional, partindo do estudo da história da língua e de seu conhecimento para chegar à compreensão da sociedade nacional.

A autora começa, portanto, tratando - na Primeria Parte do livro, destinada às relações entre língua, ética e política - de processos de significação que produzem sentidos para a língua nacional no contexto do contato entre culturas (americana e européia). Um fato evidente é que o português do Brasil e o de Portugal - apesar de se tratar de uma mesma língua - passaram por diferentes processos históricos, resultando numa distinção entre os dois falares: "o brasileiro significa diferentemente do português ao significar em português. Eis a duplicidade constitutiva, a heterogeneidade, a polissemia na própria base do exercício da língua: o português e o brasileiro não têm o mesmo sentido. São língua materialmente diferentes" (p. 26). Por isso, pode-se afirmar que o português do Brasil não é apenas uma contextualização do português de Portugal, mas é uma "historicização singular, efeito da instauração de um espaço-tempo particular diferente do de Portugal" (p. 30).

Passando especificamente a tratar do chamado português macarrônico, a partir de um poema paródico de Juó Bananére (Migna Terra), a autora define esse registro como "uma paródia da língua portuguesa, que reflete a imagem que o brasileiro tem do português do Brasil falado por imigrantes italianos no Brasil" (p. 34). Outro assunto tratado pela autora é a relação entre ética e significação, já que a questão da ética ultrapassa os limites da conduta e atinge a própria produção do significação, incidindo sobre a relação da língua com a constituição dos sentidos e dos sujeitos. A autora trata ainda do sujeito na história e no simbólico, destacando sua importância para a história das idéias: "pensar a história das idéias é tomar em conta, e de maneira particular, a ideologia, a historicidade, a memória, o que é impossível sem pensar o sujeito e o modo como ele se constitui, se subjetiva, se identifica ante o simbólico" (p. 73). Sobre a relação entre ética e política das línguas, analisa a atuação do Summer Institute of Linguistic na América Latina até os anos oitenta, estendendo a discus- 
são para uma questão mais abrange de política lingüística. Em capítulo sobre lexicologia discursiva, Eni Orlandi lembra que os discursos lexicográficos (lista de palavras, dicionários etc.) fazem parte do processo de gramatização de uma determinada língua, representando as relações do falante com a língua nacional. Nesse sentido, analisa o discurso lexicográfico dentro da perspectiva da Análise do Discurso, como "textos produzidos em certas condições tendo seu processo de produção vinculado a uma determinada rede de memória diante da língua" (p. 103). Considerando que o dicionário é ideologicamente organizado, a autora lembra que a percepção que se tem de si é que se trata de uma obra cuja marca principal é não possuir ideologia, já que representaria uma língua perfeita, completa e homogênea. Tal fato pode ser exemplificado com o caso do Brasil, onde, no século XIX, o dicionário procurava destacar as diferenças do português brasileiro com o lusitano, fenômeno que deixou de ocorrer no século XX, passando-se de um sentido de nacionalidade para um de legitimidade científica.

Na Segunda Parte de seu livro - que trata da relação entre conhecimento lingüístico, filologia e gramática -, a autora destaca a importância de se abordar a gramática a partir da articulação da história das idéias lingüísticas com a história da constituição da língua nacional, o que implica a adoção de procedimentos específicos, os quais investigam o processo de gramatização das línguas, isto é, sua instrumentação por meio de dicionários, vocabulários, enciclopédias e gramáticas. Neste sentido, ressalta que os estudos lingüísticos passam a ser uma questão caracteristicamente brasileira a partir do século XIX, época em que se estabelece a oposição entre o português brasileiro e o lusitano e, conseqüentemente, começam a ser produzidas gramáticas brasileiras da língua portuguesa.

Analisando a constituição de gramáticas em São Paulo e no Rio de Janeiro, a autora afirma que, durante o século XIX, enquanto a filiação gramátical paulista era basicamente histórica, a carioca era basicamente filosófica. No conjunto de gramáticas produzidas a partir de fins do século XIX, poder-se-ia, portanto, estabelecer dois grupos distintos: um que toma a gramática como expressão do pensamento geral, também filiada ao comparativismo (como Júlio Ribeiro e Eduardo Carlos Pereira); outro, que se filia às gramáticas históricas (como João Ribeiro e Pacheco Silva/Lameira de Andrade). De qualquer maneira, pode-se ver a 
escrita das gramáticas no século XIX como parte da constituição da sociedade nacional.

Especificamente sobre Júlio Ribeiro, a autora afirma tratar-se de um gramático que se situa no campo da reflexão lingüística, ultrapassando o mero normativismo gramatical; suas referências ao normativismo enquadram-se na tentativa de afirmação de uma legitimidade que opõe o português brasileiro ao lusitano. Fato semelhante, isto é, de afirmação de nossa identidade, pode ser ainda percebido em João Ribeiro, embora haja uma diferença entre seu enfoque gramatical (a gramática como regras da linguagem) e o de Júlio Ribeiro (a gramática como fatos da linguagem). Procurando aliar as perspectivas filósofica (de Júlio Ribeiro) e histórica (de João Ribeiro), encontra-se Eduardo Carlos Pereira, com o predomínio do discurso pedagógico. Estas e outras características das gramáticas do período mostram uma particular forma de circulação e de autoria inscrevendo-se num determinado contexto social -, autoria que será questionada pela instituição da Nomenclatura Gramatical Brasileira: "ser autor de gramática no século XIX no Brasil é assumir a posição de um saber lingüístico que não reflete meramente o saber gramatical português. Nesse mo- mento, o da irrupção da República, não basta que o brasileiro saiba sua língua, é preciso que, do ponto de vista institucional, ele saiba que sabe. A gramática, dessa perspectiva, é o lugar em que se institui a visibilidade desse saber legítimo para a sociedade" (p. 157). Por isso a assunção da autoria brasileira das gramáticas de língua portuguesa alia-se, no século XIX, à idéia de constituição de uma indentidade nacional, passando, no século XX, à idéia de manutenção dessa identidade. A instituição da NGB (Nomenclatura Gramatical Brasileira) representa uma inflexão nesse processo autoral, já que desautoriza as variedades de concepção existentes entre os gramáticos, promovendo um processo de uniformização.

Passando, em seguida, por assuntos diversos, das gramáticas de Eduardo Carlos Pereira ao Colégio Culto à Ciência, a autora faz considerações acerca da Gramática, da Filologia e da Lingüística, ressaltando que o autor de gramática, no Brasil do século XIX, é caracterizado por assumir uma posição de independência, libertando-se de um saber lingüístico que é mera reprodução do português. Assim, ao se delocar para o Brasil o saber gramatical do português, são elaborados novos modos de significar e elaborar esse conhe- 
cimento: "No século XIX, momento de ruptura com a filiação portuguesa e de estabelecimento das bases para a produção das gramáticas brasileiras, os gramáticos asseguram nossa identidade lingüística nacional, e afirmam nossa identidade de cidadão na sociedade brasileira. O surgimento da posição-autor gramático brasileiro, produz um conhecimento legítimo da língua que corresponde a um gesto de apropriação da própria língua, e legitima a relação do brasileiro com a escrita. Ao assinar a gramática, os gramáticos brasileiros, no século XIX, tomam posição no movimento social de construção da história brasileira na formação do Estado, na organização da sociedade brasileira com suas instituições em que as do saber ocupam um lugar importante, e, finalmente, assumem uma posição na história das idéias" (p. 192).

Segundo a autora, no início do século XX, o Estado brasileiro já se tinha definido, bem como tinham-se definido nossas diferenças lingüísticas, em relação a Portugal. Produziu-se, então, grande quantidade de gramáticas, como diferenças de natureza descritiva e analítica, desencadeando assim o aparecimento da Nomenclatura Gramatical Brasileira (1957/1958), impondo-se uma homogeneidade terminológica, a qual acaba por apagar a materialidade da função de autor gramatical, característica do século XIX: "nessa perspectiva, e como parte desse processo, a NGB resultou de uma intervenção direta do Estado que produziu a homogeneização, a fixação da terminologia gramatical no Brasil. Com a NGB, os gramáticos foram despossuídos dos lugares de autor que tinham no século XIX. A NGB cristalizou a gramática, ou melhor, ela reduziu a gramática a uma nomenclatura fixada e o gramático perdeu seu estatuto de autor, ou, pelo menos, perdeu uma sua forma de autoria. As diferentes e variadas posições dos gramáticos do século XIX que tomavam a cargo a responsabilidade de um saber sobre a língua - com as diferentes filiações teóricas, trabalhando as diferenças entre gramática geral, gramática histórica, gramática analítica, gramática descritiva etc. - são desautorizadas pelo Estado brasileiro. No século XX, há transferência desse lugar de invenção para os lingüistas: onde o lugar do autor de gramática é esvaziado de sua importância pela NGB se situa o lingüista como produtor de conhecimento científico sobre a língua. Daí em diante, o saber do gramático deve ser caucionado pelo lingüista" (p. 193). 
Nesse percurso, torna-se cada vez mais requisitado um conhecimento científico da língua, dando ao discurso lingüístico maior legitimidade, direcionando o enfoque do debate em torno da grmática para a disputa não mais entre brasileiros e portugueses, mas entre brasileiros e brasileiros.

A autora trata, finalmente, de assuntos direta ou indiretamente ligados àqueles aqui tratados até agora, como a relação entre mercado e interesse no conhecimento sobre a linguagem; a relação entre o discurso e a História do Brasil, sobretudo na constituição do cidadão brasileiro; a escrita e a educação na sociedade indígena; a ligação entre a cidade e a escola; a abordagem da ideologia positivista, a partir de alguns se seus discursos ideológicos; e o discurso naturalista, presente na escrita dos viajantes que estiveram no Brasil durante o século XIX.
Empregado conceitos retirados da Análise do discurso (como os de condições de produção, sujeito do discurso etc.), ramo de estudos da qual também é uma das principais divulgadoras no Brasil, Eni Orlandi revela desde o princípio sua dívida para com um cabedal teórico proveniente dessa tendência analítica, buscando conciliá-la com a Historiografia Lingüística e aplicar seu resultado no estudo das idéias lingüísticas difundidas no Brasil, sobretudo no chamado português brasileiro.

Por estes e outros méritos, sua obra constitui leitura imprescindível a quem quiser conhecer mais a fundo o largo percurso trilhado pela história das idéias lingüísticas no Brasil e seus inumeráveis desdobramentos. 